\title{
Investigating underlying factors of collaboration for construction projects in emerging economies using Exploratory Factor Analysis
}

\author{
Hazhar Faris, Mark Gaterell and David Hutchinson. \\ School of Civil Engineering and Surveying, University of Portsmouth, Portsmouth, United \\ Kingdom.
}

\section{Investigating underlying factors of collaboration for construction projects in emerging economies using Exploratory Factor Analysis}

\begin{abstract}
Competing relationships and a lack of collaboration are common in the construction industry. Consequently many reasons, such as lack of trust, unfair risk sharing and ineffective communication are highlighted by actors as challenges in the construction sector. Collaboration has been demonstrated as a solution for these challenges for the construction industry. However, collaborative environments are still far from effective in emerging economies with a lack of research and information available for such countries. We have used the Kurdistan region of Iraq to investigate and explore these challenges using systematic enquiry, utilising quantitative and qualitative methods. This article aims to explore these challenges, by reviewing past literature and investigating construction practices to better quantify those factors that underlie collaboration. A comprehensive review of the literature was conducted to identify the most critical factors. Then, a questionnaire was used to survey the opinions of practitioners, analysed through Exploratory Factor Analysis. Six factors were identified: project vision, participant behaviour, communication, relationship definition, contractual agreements and systematic process. Additionally, the paper provides suggestions as to how industry might apply such factors. This article contributes to a scarce literature regarding construction projects in Kurdistan region and emerging economies in general.
\end{abstract}

Keywords - Collaboration, critical factors, construction, project management, factor analysis, emerging economies, Kurdistan, Iraq. 


\section{Introduction}

In the construction industry, many organisations work together to deliver the products required by clients. To accomplish this, they need to collaborate and depend on each other (Liu et al. 2017). Globally, the construction industry is more fragmented than other industries such as the manufacturing sector and has more difficulties in terms of relationships and collaboration (Phua 2006). Many researchers have explained that the construction industry has an absolute need for collaboration between stakeholders, such as clients, contractors and designers (Hughes et al. 2012; Grilo et al. 2013; Motawa and Carter 2013; Liu et al. 2017). Managing relationships between different parties in collaborative ways could move organisations toward achieving their goals and delivering better projects (Kożuch 2009). In contrast, continued use of traditional means of project delivery, which lack collaboration, could result in serious quality defects in construction projects (Arditi and Gunaydin 1998).

The construction industry has passed through three main delivery systems: traditional construction management (TCM), the project management (PM) model and partnering (Xue et al. 2010). The TCM approach is a competition between independent parties to win competitive bids and project responsibilities are based on strict contractual clauses. In this traditional approach, there is no shared vision between parties and each organisation defends their own interest. The TCM delivery system has resulted in many difficulties such as delays, cost overruns, win-lose culture and adversarial relations (Chan et al. 2004). To overcome the issues of TCM, PM has been used. PM models try to control cost, time and quality in a project-based system to achieve client needs; however, this approach also has faced many difficulties (Shen and $\mathrm{Wu} 2005)$.

After an investigation to solve the problem of fragmentation and underperformance in the UK construction industry (Latham 1994), partnering was suggested as a solution to replace traditional methods of project delivery. Partnering delivered better results than traditional 
approaches to project management. However, relationships in partnering still need to be improved to overcome the underperformance of construction industry projects (Meng 2012). Many authors have insisted that the construction industry needs to improve collaboration and to adopt new ways of working to remain competitive and meet the expectations of increasingly demanding clients (Shelbourn et al. 2007; Cao et al. 2015; Morrell 2015).

While problems of fragmentation and lack of collaboration in construction exist globally, the case is more severe in developing economies, where the construction sector is more fragmented. Additional problems confront construction projects in these countries, compared to developed economies, which include social, cultural, organisational, economic and process-related obstacles (Ofori 2000; Elkhalifa 2016; Haron et al. 2017). This observation is apparent in the Kurdistan region of Iraq, where the construction process has been found to be highly uncommunicative, with a significant lack of collaboration between stakeholders. This lack of interaction between participants has resulted in many shortcomings in construction projects such as deviations in construction and design (Zebari and Ibrahim 2016). This article aims to address this issue by identifying the critical factors needed to improve collaboration in construction projects in developing economies, especially in Iraqi Kurdistan.

\section{Benefits of collaboration in the construction industry}

Collaboration can have immense benefits in the construction industry, whether external, such as helping organisations overcome competitive markets competitions or by providing internal stability (Hughes et al. 2012). According to Black et al. (2000), the main benefit of collaborative working is less adversarial relationships between parties, thereby reducing the conflicts in supply chains of the construction industry. Adversarial relationships in traditional routes are the cause of many issues that still exist in the construction industry, such as delays and underperformance of projects (Akintan and Morledge 2013). Improving relationships and 
moving away from a win-lose culture could result in significant improvements in performance, whether this is financial performance for construction companies or asset performance for clients.

Collaborative working is vital to achieving long-term business objectives and continuous improvements (Eriksson 2010). Continuous improvement could ensure future work and long-term relationships between parties. These relationships between construction industry firms are crucial to gaining economic benefits. Vaaland (2004) explained the role of collaboration in resolving different views between parties that can produce well-developed business relationships, which leads to reduced loss of productivity and minimised costs. Ultimately, economic targets become possible when effective relationships are maintained among industry stakeholders.

Clearly, combining the resources and expertise of stakeholders could lead to increasing the efficiency of teams and delivering higher quality products. The involvement of suppliers and subcontractors at the right time in projects brings practical knowledge to the teams and helps prime contractors and clients to control performance issues (Bemelmans et al. 2012). Fragmentation and involvement of multiple professional such as designers, clients, contractors and subcontractors in the construction industry have caused low-levels of customer satisfaction. Morrell (2015) insisted that collaboration between different parties will resolve performance issues and lead to a higher level of customer satisfaction. Delivering end users' needs is one of the main aims of project teams to ensure the success of their organisations in construction markets. Akintoye et al. (2000) emphasised that improved customer services and cost objectives are the main benefits of collaborative working processes.

Despite improving project processes and team culture, another significant benefit of collaborative approaches is schedule reduction and improved time scales (Bresnen and Marshall 2000a). One of the main problems with construction projects is delays; keeping up 
with schedules is always a difficult task. Many issues in construction projects such as deficiencies in control mechanisms and delays are considered as the result of a lack of teamwork in traditional approaches (Koraltan and Dikbas 2002). Construction teams could overcome this issue and deliver projects to a planned timetable by using an effective collaboration process and the experience of all teams.

Construction parties have lower exposure to risks when collaboration is developed between teams. In collaborative working practices, risk and rewards are shared; if a party is at risk of losing their rewards, then all parties may be at risk based on principles of gain-pain sharing (Yeung et al. 2007). This approach encourages parties to cooperate with other parties at risk and reduce the overall 'pain' to a minimum. Furthermore, Rahman et al. (2014) emphasised the role of improved teamwork and open communication to simplify the construction process. Design complexity is a common issue within construction projects that can be solved by producing a collaborative environment between the design and construction teams. This collaboration will expand the awareness of construction teams toward design details and will also increase the buildability of the design. For example, the involvement of contractors in the design phase facilitates the process and can raise constructability as well as maximising value engineering (Bresnen and Marshall 2000b).

\section{Construction projects in the Kurdistan region and lack of collaboration}

The construction industry is fundamental to any economy; it provides the infrastructure and builds an environment that enables a population to flourish socially, culturally and economically (Chan et al. 2004; Winch 2010). The contribution of construction is increased in the case of emerging economies (Ofori 2000; Giang and Pheng 2011) where economic development is led by a high volume of construction projects (Ofori 2007). In Iraqi Kurdistan, construction projects have an additional role in restoring the nation's internal built 
environment, replacing housing, and securing essential resources such as water, power and sewage. At the same time, it is creating the necessary infrastructure such as transport systems to improve inter-regional connections and international connectivity, facilitating much-needed international investment (RTI International 2008). The construction industry acts as a significant contributor to job prospects, and to building gross domestic product (GDP) and the economy of the region.

In the Middle East, construction projects are going through a process of change and development, many companies from different countries work in that industry (Gerges et al. 2017). This process of change has resulted in many issues in construction projects such as inconsistent processes and deficiencies in collaboration. Similarly, the limited literature on construction projects in the Kurdistan region shows that a significant lack of collaboration exists between participants, which has resulted in an inadequate construction process in the sector. For example, Faris (2015) found that a lack of collaboration and the fragmentation of the industry are among the main reasons for projects not performing as expected and for construction delays in this region. The main issues causing projects to underperform include ineffective communication, lack of contractor involvement, the lack of design information available, inadequate planning and weakness of supply chains. These results concur with those from Muhammed (2015). Despite their paramount importance, construction projects in the Kurdistan region have many shortcomings in performance and have not met required levels of customer satisfaction (Mustafa 2017). Such difficulties include adversarial relationships, lack of communication, and socio-cultural, technical and management issues (RTI International 2008). Zebari and Ibrahim (2016) added that in many cases contractors carry out tasks without any collaboration with other participants involved in related tasks or without considering the design requirements. 
Another challenge is the lack of collaboration between design and construction teams. According to Jamieson (2004), the primary reasons for underperforming construction projects in the region are design errors and the construction process, which do not meet design intentions. In addition, Bell (2014) suggested that growth of the sector has increased the number of different stakeholders in construction projects with the associated need to improve relationships and collaboration between the parties involved over the whole project lifecycle. To solve the problem of fragmentation of the industry and to develop collaborative working, construction practitioners need to improve many aspects of working. In order to improve collaboration, a range of factors need to be considered as means of overcoming project issues, not least because establishing new ways of working can be challenging and a range of potential barriers might need to be overcome (Koraltan and Dikbas 2002; Shelbourn et al. 2007).

Research into factors of collaboration is still at its infancy in the Middle East. Limited research exists on factors of collaboration, for instance, Koraltan and Dikbas (2002) Dikmen et al. (2008) in Turkey and Bidabadi et al. (2016) in Iran have explored factors for improving collaborative approaches. However, in the context of the Kurdistan region, there is an immense gap in the literature toward improving collaboration in construction projects. Researchers have yet to investigate and to determine local factors of collaboration. This research aims at filling this gap of the literature by identifying a set of local factors for developing collaborative environments.

\section{Preliminary factors of collaboration}

This study provides an in-depth review of the literature regarding articles relating to collaboration from 2000 to 2018. Firstly, the related articles were identified through searching for keywords, such as factors for partnering, alliancing, strategic alliancing, teamwork and collaboration, in titles and abstracts of studies. Secondly, all related articles were qualitatively 
evaluated in order to determine a representative sample for the study. Similar approaches were adopted by other researchers such as Kożuch and Sienkiewicz-Małyjurek (2016) and Wu et al. (2008) in the construction industry. The process resulted in the 35 most-closely related articles being selected for the final review, shown in Table 1. Frequently mentioned factors are presented in Table 2 and briefly outlined be 
Table 1. Reviewed papers to identify factors of collaboration

\begin{tabular}{ccc|ccc|ccc}
\hline $\begin{array}{c}\text { Ref. } \\
\text { no }\end{array}$ & Author(s) & Year & $\begin{array}{c}\text { Ref. } \\
\text { no }\end{array}$ & Authors & Year & Ref. & Author(s) & Year \\
\hline 1 & Akintoye et al. & 2000 & 13 & Lu and Yan & 2007 & 25 & Patel et al. & 2012 \\
\hline 2 & Black et al. & 2000 & 14 & Shelbourn et al. & 2007 & 26 & Akintan and Morledge & 2013 \\
\hline 3 & Bresnen & 2000 & 15 & Yeung et al. & 2007 & 27 & Meng & 2013 \\
\hline 4 & Bresnen & $2000 \mathrm{~b}$ & 16 & Dikmen et al. & 2008 & 28 & Rahman et al. & 2014 \\
\hline 5 & Cheng et al. & 2000 & 17 & Erdogan et al. & 2008 & 29 & Azhar et al. & 2014 \\
\hline 6 & Bayramoglu & 2001 & 18 & Koutsikouri et al. & 2008 & 30 & Gassel et al. & 2014 \\
\hline 7 & Cheng and Li & 2001 & 19 & Wu et al. & 2008 & 31 & Bidabadi et al. & 2015 \\
\hline 8 & Cheng and Li & 2002 & 20 & Eriksson & 2010 & 32 & Bidabadi et al. & 2016 \\
\hline 9 & $\begin{array}{c}\text { Koraltan and } \\
\text { Dikbas }\end{array}$ & 2002 & 21 & Xue et al. & 2010 & 33 & Kozuch and & 2016 \\
\hline 10 & Chan et al. & 2004 & 22 & Bemelmans et al. & 2012 & 34 & Koolwijk et al. & 2018 \\
\hline 11 & Vaaland & 2004 & 23 & Hughes et al. & 2012 & 35 & Nursin et al. \\
\hline 12 & Nystrom & 2005 & 24 & Meng & 2012 & & 2018 \\
\hline
\end{tabular}


Table 2. Factor of collaboration and resources mentioned

\begin{tabular}{|c|c|c|c|}
\hline Rank & $\begin{array}{l}\text { Factors of } \\
\text { Collaboration }\end{array}$ & Freq. & $\begin{array}{c}\text { No. of papers (from table } 1 \text { ) } \\
\text { mentioned the factor }\end{array}$ \\
\hline 1 & Trust & 31 & $\begin{array}{c}\text { ([1],[2],[3],[4],[5],[6],[7],[8],[9],[10],[12],[13], } \\
{[14],[15],[16],[17],[18],[19],[21],[22],[23],[24],} \\
[25],[26],[27],[28],[29],[31],[33],[34],[35])\end{array}$ \\
\hline 2 & Communication & 26 & $\begin{array}{c}([2],[4],[5],[6],[7],[8],[9],[10],[14],[15],[16], \\
{[18],[19],[21],[22],[23],[24],[25],[27],[28],[30],} \\
[31],[32],[33],[34],[35])\end{array}$ \\
\hline 3 & Conflict resolution & 21 & $\begin{array}{c}([5],[6],[7],[8],[9],[10],[11],[12],[13],[15],[16], \\
[17],[19],[21],[23],[24],[25],[27],[28],[29],[35])\end{array}$ \\
\hline 3 & Mutual goals & 20 & $\begin{array}{c}([1],[4],[5],[9],[10],[12],[13],[14],[15],[18],[19], \\
[21],[22],[23],[24],[25],[27],[28],[29],[33])\end{array}$ \\
\hline 5 & $\begin{array}{l}\text { Top management } \\
\text { support }\end{array}$ & 20 & $\begin{array}{c}([1],[2],[5],[7],[8],[10],[12],[13],[15],[16],[20], \\
[19],[21],[22],[25],[28],[29],[31],[32],[34])\end{array}$ \\
\hline 6 & Commitment & 19 & $\begin{array}{c}([1],[2],[3],[5],[7],[8],[10],[13],[14],[15],[16], \\
[19],[22],[25],[28],[31],[32],[33],[34])\end{array}$ \\
\hline 6 & Gain-pain sharing & 18 & $\begin{array}{c}([1],[2],[3],[6],[9],[13],[14],[15],[19],[20],[21], \\
[22],[23],[24],[27],[28],[29],[34])\end{array}$ \\
\hline 8 & Culture & 16 & $\begin{array}{c}([1],[2],[4],[5],[9],[13],[14],[16],[18],[21],[22], \\
[25],[29],[31],[33],[35])\end{array}$ \\
\hline 9 & Resource sharing & 14 & $\begin{array}{c}([5],[7],[8],[10],[12],[13],[14],[15],[17],[19], \\
[25],[26],[28],[33])\end{array}$ \\
\hline 10 & $\begin{array}{l}\text { Early involvement of } \\
\text { key participants }\end{array}$ & 14 & $\begin{array}{c}([4],[5],[6],[10],[12],[14],[15],[20],[21],[23], \\
[25],[29],[31],[34])\end{array}$ \\
\hline 11 & Clear roles & 13 & $\begin{array}{c}([2[,[4],[10],[14],[16],[18],[23],[25],[27],[28], \\
[31],[32],[33])\end{array}$ \\
\hline
\end{tabular}

\section{Trust}

Trust is a major component required for delivering a successful process of collaboration (Koolwijk et al. 2018). It is essential that construction managers focus on social interactions as a means to build trust and respect between practitioners in order to establish a collaborative workplace (Shelbourn et al. 2007). These personal interactions are necessary to find new ways of working and move away from hard contractually-guided relations. Construction managers 
should notice that building trust between individuals is essential to building trust between organisations. Yeung et al. (2007) agreed that trust is based on previous experience either directly, with people concerned, or indirectly, by anticipated or projected experiences. Therefore, trust is an emotional and human situation that is necessary for every team to achieve successful business relationships. Gaining higher levels of trust after working together in a project reveals the level of success of collaborative relationships between involved parties (Cheng and Li 2002).

\section{Communication}

A lack of open communication is the main reason for failures in construction projects, hence, it is essential to have well-established communication lines to avoid performance issues and cost overruns (Meng 2012). Black et al. (2000) argued that good communication is the most important factor for construction sites considering a large number of problems that occur as a result of poor communication between client, contractor and consultants.

It is noticeable that the importance of communication has increased in construction projects with the implementation of new ways of working and using complex designs. For instance, Koutsikouri et al. (2008) insisted that rich communication is crucial in design stages to provide shared understanding and simplify complicated design details. The research added that communication underpins all other factors needed for collaborative working. Moreover, van Gassel et al. (2014) explained that it is fundamental to enable effective communication lines to gain efficient processes of collaboration. To do so, regular meetings could be used as a means to gain efficient communication (van Gassel et al. 2014).

\section{Mutual goals}

Akintoye et al. (2000) described mutual interest as a key factor to provide a collaborative environment between different levels of working chains in construction teams. It is not possible 
for construction parties to work collaboratively and gain benefits without setting common targets (Dikmen et al. 2008). Hence, all parties are required to attain common goals and consider each other's interests in order to achieve business profits (Kożuch and SienkiewiczMałyjurek 2016).

\section{Conflict resolution}

A proper conflict resolution system is crucial for collaboration to survive between construction parties. In conflictual events, resolving tense relationships is important to avoid a total breakdown of the interaction and work termination between stakeholders (Vaaland 2004). The author argued that solving a conflict between parties with different perceptions could be used as a means to enhance collaborative relationships. Since conflicted parties need to explain reasons for a different view, this may find the underlying causes of the conflict and prevent it from happening again. It is necessary for construction teams to solve conflicts at the lowest possible level before it reaches legal authorities (Bayramoglu 2001).

\section{Top management support}

Top management support is essential to develop relationships and increase confidence between parties because it supplies resources, finance, information and time (Cheng and Li 2001). Top management is required to lead and arrange activities in construction projects and assure that the process is working effectively (Nyström 2005). Actually, the first step to producing collaboration in construction projects should come from top management through expressing support and commitment to goals (Bidabadi et al. 2015). Lack of support from management could result in the growth of small issues that become big obstacles to the proceeding process.

\section{Commitment}

As the construction industry struggles with adversarial relationships, practitioners need a 
commitment to common goals to help them adopt collaborative approaches (Bidabadi et al. 2016). It has been illustrated that parties need to show a long-term commitment to common visions in order to attain stability within projects and to achieve project goals. Committed stakeholders prefer long-term achievement to a small immediate benefit, which reduces the possibility of rising disputes from different working tasks. Setting common goals, even if it is an early stage of the project, does not benefit businesses if parties are not fully committed Bemelmans et al. (2012).

\section{Gain-pain sharing}

A large number of obstacles on construction projects stem from unfair risk sharing in oldfashioned contractual clauses (Koraltan and Dikbas 2002). The construction industry needs to find effective ways to share risks and rewards between its parties in order to be able to improve adversarial relationships. Implementation and adoption of new ways of working depend on parties' obligations to share the profits of target achievements and simultaneously to bear the risks of missing that goal (Azhar et al. 2014).

\section{Culture}

Culture is a very influential factor on collaboration in every organization. Organisational characteristics such as regulations, organisational structure, leadership and organisational culture have a strong influence on the efficacy of collaboration within the organisations (Kożuch and Sienkiewicz-Małyjurek 2016). Nursin and Latief (2018) argued that in order to build a collaborative workplace, leaders need to explain collaboration as a culture or the way the organisation works for the members of the project.

\section{Resource sharing}

Sharing resources creates an atmosphere of collaboration that is more harmonious and 
effective, and parties need to increase the level of resource sharing to avoid deficiencies in the performance of projects (Akintan and Morledge 2013). In addition, it is important for construction projects to share resources in a proper way to avoid deficiencies in resources for different tasks. Management teams need to use resources in an appropriate way to avoid any failure in the implementation of collaboration (Erdogan et al. 2008).

\section{Early involvement of key participants}

In many cases, the early involvement of some key participants such as contractors, subcontractors and suppliers is restricted under old contract approaches. This lack of involvement of key participants has resulted in a lack of practical experience in design stages; consequently, this leads to deficiencies in the buildability of designs. Eriksson (2010) explained that it is crucial to involve contractors and subcontractors as early as possible to negotiate directly with the design team to avoid performance issues. Chan et al. (2004) agreed that despite the involvement of contractors, major subcontractors need to be brought in as well at an early stage of projects so that parties will develop collaborative relationships at the start.

\section{Clear Roles}

Another core contributor to the success of a collaborative approach is clearly defined roles and responsibilities of members in projects (Patel et al. 2012). It is important for construction teams to understand that each individual has a different role and should be respected by others (Black et al. 2000). Besides clarifying roles, construction teams need to have some flexibility in roles because many issues that arise in traditional ways of contracting are due to a high level of specialisation in role definition, which has resulted in a lack of support between team members. A significant step toward effective collaboration in construction projects is to eliminate duplication in responsibilities and increase flexibility in the roles of members (Bresnen and Marshall 2000a). 


\section{Research Methodology:}

A combination of a literature review, pilot studies and an empirical survey questionnaire were adopted in this research. Firstly, in the qualitative phase, the literature review was used to (1) understand the state-of-art practices in the construction industry regarding collaborative environments, (2) to identify a set of potential factors of collaboration from the global literature, (3) to explain the research gap and to identify the need for establishing local factors. Outcomes of the review were used to develop a questionnaire survey. Later, in the pilot studies, interview-administrated questionnaires were used to gain construction practitioners' views on the design and contents of the questionnaire. Consequently, the final empirical questionnaire was developed for the quantitative phase, explained in the next section. Similar approaches were found to be effective for investigating characteristics of the construction sector (Lu and Yan 2007; Meng 2013). Figure 1 shows the research framework for this study.

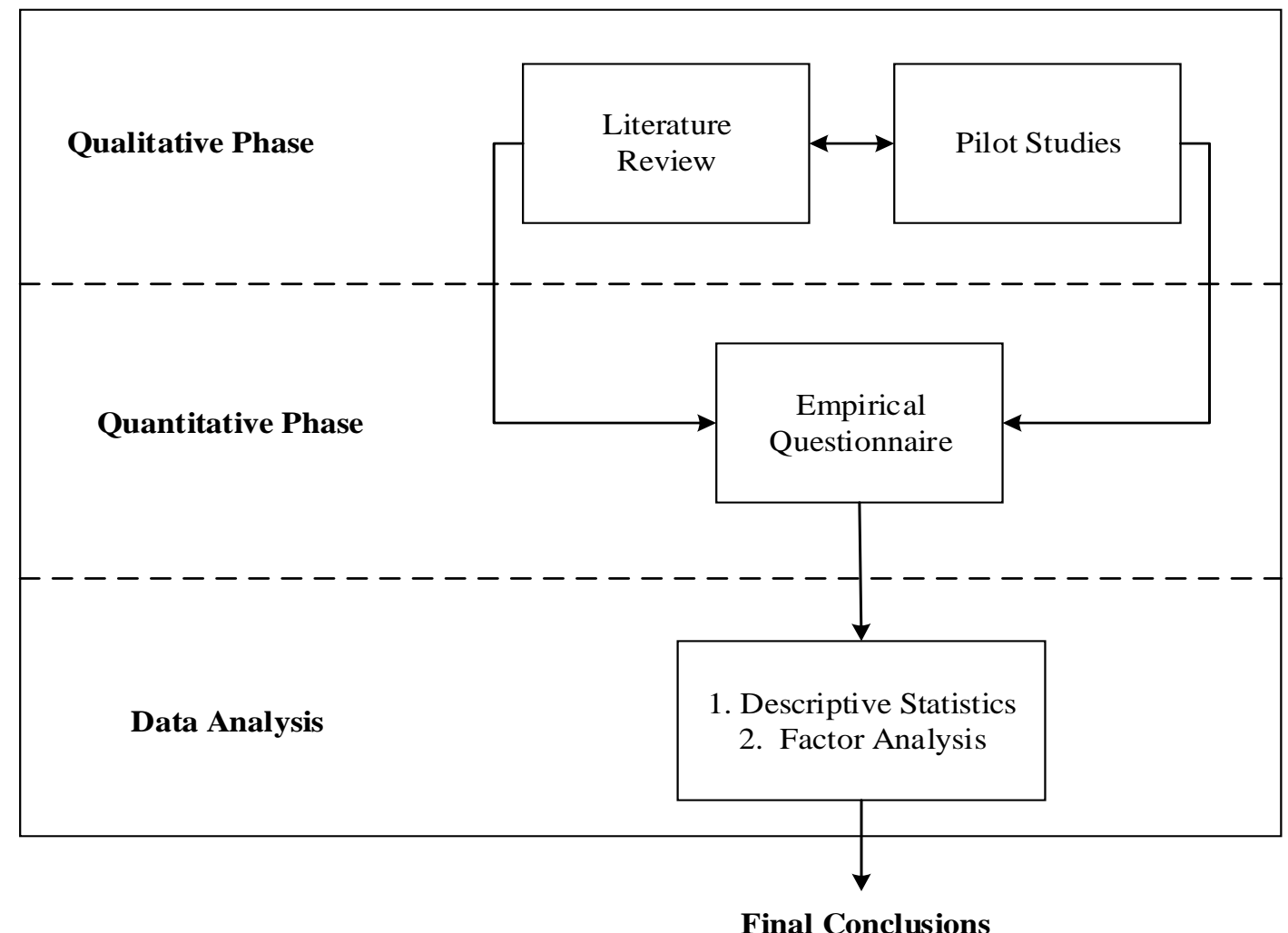

Figure 1: Research framework 


\section{Questionnaire survey}

The factors derived from the literature were used to develop an empirical questionnaire survey. The survey instrument aimed to establish local factors of collaboration using the opinion and experience of construction practitioners. Firstly, pilot studies were undertaken and the questionnaire delivered to 21 construction experts seeking their opinions about survey design and the factors considered. In pilot studies, respondents were given a chance to add any extra factor that they thought should be considered. Then, the questionnaire was refined and the revised instrument was prepared for the final empirical study. Besides gathering information about the profile of participants, the questionnaire included 23 items to investigate improving collaboration as shown in Table 6. The respondents were asked to rate the importance of all factors for improving collaboration in construction projects, using a five-point Likert scale ( $1=$ the least important to $5=$ the most important). To identify potential respondents and to ensure a representative sample for the study, responsible organisations were contacted such as the Ministry of Construction and Housing and the Kurdistan Contractors Union. Potential respondents were identified based on information received from those organisations. Respondents were required to be active professionals involved in public or private sectors of housing in the Kurdistan region. Additionally, all participants needed to hold key positions in their organisations. Accordingly, around 750 questionnaires were delivered to potential respondents in hard and soft copies. After collecting data and the initial screening 227 questionnaires were included in the final data analysis. This process resulted in a response rate of $30.2 \%$. The profile of respondents is shown in Table 3. Descriptive statistics were used to understand the data sample collected. Table 4 shows details of descriptive analysis for ordinal data variables. All data analysis was carried out using Statistical Package for the Social Sciences (SPSS 24). 
Table 3. Profile of respondents to the questionnaire survey

\begin{tabular}{|c|c|c|c|c|c|}
\hline \multicolumn{3}{|c|}{ Years of experience in construction } & \multicolumn{3}{|c|}{ Type of the job } \\
\hline & Frequency & Percentage & & Frequency & Percentage \\
\hline Less than 5 & 44 & 19.4 & $\begin{array}{l}\text { Client's } \\
\text { Representative }\end{array}$ & 38 & 16.7 \\
\hline $6-10$ & 81 & 35.7 & Project Manager & 74 & 32.6 \\
\hline $11-15$ & 44 & 19.4 & Design Team & 38 & 16.7 \\
\hline more than 15 & 58 & 25.6 & Main Contractor & 32 & 14.1 \\
\hline \multirow[t]{3}{*}{ Total } & 227 & 100 & Sub-Contractor & 12 & 5.3 \\
\hline & & & Other & 33 & 14.5 \\
\hline & & & Total & 227 & 100 \\
\hline
\end{tabular}

Table 4. Descriptive analysis for ordinal data

\begin{tabular}{lcccc}
\hline Items number & \multicolumn{2}{c}{$\mathrm{N}=227$} & Median & Mode \\
\cline { 2 - 3 } & Valid & Missing & & \\
\hline 1 & 227 & 0 & 4.0 & 4 \\
2 & 227 & 0 & 4.0 & 4 \\
3 & 226 & 1 & 4.0 & 4 \\
4 & 227 & 0 & 4.0 & 4 \\
5 & 227 & 0 & 4.0 & 5 \\
6 & 226 & 1 & 3.0 & 4 \\
7 & 225 & 2 & 4.0 & 4 \\
8 & 226 & 1 & 4.0 & 4 \\
9 & 226 & 1 & 4.0 & 4 \\
10 & 227 & 0 & 4.0 & 4 \\
11 & 227 & 0 & 4.0 & 4 \\
12 & 227 & 0 & 4.0 & 4 \\
13 & 226 & 1 & 4.0 & 4 \\
14 & 227 & 0 & 3.0 & 4 \\
15 & 227 & 0 & 4.0 & 4
\end{tabular}




\begin{tabular}{lllll}
16 & 227 & 0 & 4.0 & 4 \\
17 & 227 & 0 & 4.0 & 5 \\
18 & 227 & 0 & 3.0 & 4 \\
19 & 227 & 0 & 4.0 & 4 \\
20 & 227 & 0 & 4.0 & 5 \\
21 & 227 & 0 & 4.0 & 5 \\
22 & 227 & 0 & 4.0 & 4 \\
23 & 227 & 0 & 4.0 & 5 \\
\hline
\end{tabular}

\section{Factor Analysis}

Exploratory Factor Analysis (EFA) was used to identify the underlying factors that contribute to the success of collaboration. EFA is a dimension reduction technique used to reduce data to a more manageable size while retaining as much information as possible (Field 2013). This multivariate technique is used to investigate the underlying structure of relations or correlations among a large set of variables to yield a smaller number of factors. Floyd and Widaman (1995) explained that factor analysis uses a matrix of correlations or covariances among measured items to explain measured data in more general groups of latent variables. Intercorrelated variables will be combined and grouped under one cluster that is interpreted in order to represent data in a more meaningful way than initial variables.

In order to test the suitability of the sample for EFA, the Kaiser-Meyer-Olkin (KMO) test was performed. In this study, the KMO value was 0.889 , indicating that the sample is adequate to conduct factor analysis (Kaiser 1974). Also, a Cronbach's Alpha of 0.896 shows the scale reliability and internal consistency of the survey instrument (Field 2013), see Table 5. Principal Axis Factoring (PAF) with oblique rotation was used to extract underlying factors from 23 items. During extraction, PAF only accounts for shared variance between variables and excludes unique and error variances; that is the recommended method when researchers have a prior idea about the relationship between variables and try to find the underlying 
structure of factors (Costello and Osborne 2005; Brown 2009). In this research, due to undertaking a global literature review about factors of collaboration, the authors were already aware of some relationships. Thus, PAF was preferred as the extraction method. This process resulted in six factors being retained all with eigenvalues greater than one and loadings above 0.3 , based on Kaiser's criteria. The total variance explained and the factor loadings for each factor retained are shown in Table 6.

Table 5. KMO and Bartlett's Test

Kaiser-Meyer-Olkin Measure of Sampling Adequacy.

0.899

Bartlett's Test of Sphericity Approx. Chi-Square $\quad 1727.985$

\begin{tabular}{cc} 
df & 253 \\
Sig. & 0.000 \\
\hline
\end{tabular}

a. Cronbach's Alpha $\quad 0.896$ 
Table 6. Factor structure of Principal Axis Factoring

\section{Items}

Eigenvalues Factor

$\%$ of variance Cumulative $\%$

Loadings

\section{Factor 1. Project Vision}

(10) Senior management is committed to delivering the project vision

0.591

(11) Senior management is encouraging all members of the project team

0.576

to deliver the vision

(12) All involved stakeholders are committed to the project vision

(8) Key parties understand the clear and shared vision of the project

(7) Mutual goals are set between the key participants of the project

(6) Stakeholders are using ideas from different participants to improve project performance

\section{Factor 2. Behaviour of participants}

(14) The cultural difference of involved project participants affects the way they behave

(15) Each party provides the appropriate resources to deliver the project vision

(16) Each party is willing to share their resources with other parties

\section{Factor 3. Communication}

(22) The project teams are provided with enough technological resources (hardware and software packages) during the whole life of the project

(4) Communication lines are open and clear between different teams

(5) Communication lines are open and clear between members of the same team

(23) There are enough skilled staff and workers to perform different tasks in the project

\section{Factor 4. Relationship definition}

(17) The main contractor is involved at the beginning of the project life cycle

(18) The major subcontractors are brought in at an early stage of the project 
(20) Roles and responsibilities of all team members are defined at an early

(1) All involved parties in the project trust each other

(2) All parties trust that terms of the contract will be implemented

0.566

(3) The type of contract is appropriate for the project

1.031

0.361

2.105

43.860

Factor 6. Systematic Process

(13) A strategic plan of benefits and risk sharing is set between involved

0.663

parties

(19) A systematic way to evaluate the performance of the project process

0.462

is used

(21) Roles and responsibilities of participants are clear to everyone

0.438

(9) A clear process for conflict resolution is set in the project

1.019

0.391

2.087

45.947

Extraction Method Principal Axis Factoring

Rotation Method: Oblimin with Kaiser Normalizatio 


\section{Discussion of the study results}

This section outlines the results of factor analysis. Factors are ordered based on the variance shared by each factor which indicates their level of importance and their contribution to improving collaboration.

\section{Project Vision (Factor 1)}

The first factor accounted for $29.29 \%$ of the total variance and consisted of six items that can be seen in Table 6. It is essential for every project to have a clear vision to clarify its purpose, eliminate confusion and to encourage participants to contribute to the project. Construction projects need to have a comprehensive vision that is understandable by all project participants and inspires members to stay focused throughout the project life cycle. Variables under this factor show the vital role of senior management in delivering project objectives through setting mutual goals, commitment to the vision and encouraging project members to understand and to stay committed to the project vision. The primary mission of the senior management is to develop, communicate and maintain project vision in order to have successful outcomes (Christenson and Walker 2004). A project vision must be clearly understood, motivational, and credible; it also needs to be both challenging and demanding.

\section{Behaviour of participants (Factor 2)}

This factor represents $5.36 \%$ of the total variance explained and contained three variables related to cultural differences and behaviours of participants. Cultural differences have a direct effect on the way project participants behave and interact with other participants. The behaviours of participants are critical in willingness to share resources for project favour. Koutsikouri et al. (2008) indicated the critical role of participant behaviours in delivering a 
successful project and argued that careful attention must be paid to the behaviour of members in order to achieve project objectives. Collaborative working depends on a series of behaviours based on which participants interact, share resources and complete tasks (Patel et al. 2012). The behaviour of participants is an overarching factor that has an essential role at every stage of construction projects. This factor preserves its importance from the beginning of the project idea until the end of the project life cycle.

\section{Communication (Factor 3)}

Factor 3 represents $4.233 \%$ of the total variance and includes four variables that indicate the importance of clear communication lines in construction projects. It is obvious that the importance of communication is highly increased in modern construction. It is necessary to provide construction projects with enough technological resources to communicate designs and to share information between stakeholders. Alongside technological sources, construction projects are required to have an adequate number of skilled staff to deal with that technology and perform related tasks. Clarity in communication lines is crucial to develop well-connected teams with high flexibility that improve collaboration performance in construction projects (Nursin and Latief 2018). Clear communication channels are vital enablers for collaboration in construction projects that make information flow more accurate and available at the right time (Koolwijk et al. 2018).

\section{Relationship definition (Factor 4)}

This factor accounted for $2.862 \%$ of the variance and compromised of three variables which are: the main contractor involved at the beginning of the project (0.603), the major subcontractors are brought in at an early stage (0.495) and roles and responsibilities are defined at an early stage (0.389). Defining relationships between different stakeholders is necessary to have a steady process in construction projects. To obtain a well-defined 
relationship among involved parties, all related parties must be involved at an early stage; roles and responsibilities of those participants should be identified by agreement between stakeholders. Other researchers such as Shelbourn et al. (2007) and Bidabadi et al. (2015) have indicated the importance of early involvement of key stakeholders and identifying roles and responsibilities at an early stage to achieve effective collaboration.

Relationship deterioration has resulted in many issues in construction projects such as delays, cost overruns, and quality defects. The only way to overcome such problems is to define relationships in the early stages of projects by involving all related parties. The central principle of relationship definition in collaborative approaches is to establish an integrated entity that works collaboratively to achieve a mutual goal (Xue et al. 2010).

\section{Contractual agreements (Factor 5)}

The fifth underlying factor from the investigation shows the importance of contractual agreements and their contribution to building trust between parties. Managing contractual agreements in a way that increases trust between construction participants is one of the most difficult tasks in the industry. Wong et al. (2008) illustrated that adequate contractual agreements are capable of establishing trust and strengthening relationships that could have a remarkable effect on raising the performance of construction projects. Contractual agreements, through identifying fair obligations and rights, are able to reduce uncertainties and bring comfort and confidence to all affected parties. These documents need to be explainable to all stakeholders and include fair risk allocation in order to have an impact on enhancing the overall performance of project. Khalfan et al. (2007) explained that type of contact employed forms the basis of relationships and trust between contracting parties and could have a significant positive influence in increasing the performance of the construction projects. As the adversarial ways of contacting have resulted in many issues, by establishing fair contacts, the construction 
industry can move away from blame-culture, increase trust between parties and improve its outcomes (Khalfan et al. 2007).

\section{Systematic process (Factor 6)}

The last factor accounted for $2.087 \%$ of the total variance and consisted of four variables. This factor indicates that every construction project needs to have a systematic process to share risks, evaluate performance, solve conflicts and to clarify roles of members responsible for such tasks. Besides setting mutual agreements at the beginning of the projects, planning a systematic way to govern projects to achieve that goal is essential. Construction projects need to have adequate approaches to manage the process and to avoid damaging consequences (Mills 2001). A systematic process can increase confidence and certainty among involved parties.

\section{The implications for construction projects in the Kurdistan region and further study}

The construction industry in the Kurdistan region of Iraq comprises of public and private sectors. Private sector projects could show more flexibility in implementing collaboration than public sector projects. A reason for that is government policies that impose many restrictions on public construction projects. In the public sector, in most cases, contracts are awarded on a lowest-bid basis, which results in selecting unqualified contractors by focusing on reducing cost and sacrificing quality and other success criteria. Also, in traditional contracting, improving collaboration is restricted; for example, bringing in contractors and subcontractors early in the design construction process is limited. In the private sector, organisations are not faced with such solid restrictions compared to public projects and, organisations are more likely to adopt new ways of working.

Implementing new approaches such as collaboration in a conservative sector needs to be done gradually. The Kurdistan regional government (KRG) could demand that new 
approaches to be applied in public projects by imposing new policies on the construction sector through responsible governmental bodies such as the Ministry of Construction and Housing. The new rules need to make construction organisations obligated to agree on a project vision and to set a mutual goal before starting the implementation of projects. Given that the government is the client and the top management in public project, to impose new rules governmental bodies must show full support. The client and contractors need to be clear about project vision toward achieving business targets before selecting an appropriate project delivery method. It is essential that all involved parties understand and define relationships collaboratively before awarding contracts (Shelbourn et al. 2007). This can be achieved by involving contractors at an early stage and by defining relationships between involved parties. Later, through contractual agreements, as a legally-binding stage, duties can be transferred to identified organisations that meet requirements. However, contractual agreements also need to be revised and improved in order to change the adversarial construction sector into a collaborative one. For example, at the bid awarding stage, KRG can ensure that cost considerations focus on lifecycle costs, not simply the lowest initial cost. In an attempt to enable a collaborative approach in the Turkish construction sector Koraltan and Dikbas (2002) suggested that contractor selection should be based on the most economically beneficial offer, not the lowest bid. Since the lowest bid is not always the most economical option, collaboration has significant advantages related to cost reduction, this can open a way to move away from the traditional way of contacting. This involvement from the government will help the construction industry to improve construction practices and move away from the adversarial routes (Muhammed 2015).

Besides selecting the right organisations to carry out the works, to implement a project successfully, involved parties need to agree on a systematic way to deliver projects. Such systematic planning should clarify steps to solve disputes, to evaluate project performance and 
to share risks. Another factor that needs to be provided in construction projects is to make sure that communication lines are open and clear between parties. To clarify communication lines, KRG should overcome some shortcomings such as lack of technological resources and a clear lack of skilled staff (Abramzon et al. 2016). This is because technological resources are a significant element of communication channels in construction projects. This enhancement could only be achieved through strategic planning and the formation of new policies.

Construction practitioners in Iraqi Kurdistan are used to traditional ways of project delivery; consequently, they behave according to those adversarial relationships. In order to change participant behaviour toward integrated approaches and spreading the culture of collaboration, a considerable effort needs to be expended. In this process, research centres and universities could help government departments in increasing awareness toward collaborative approaches and in providing training courses for practitioners. Organising seminars and introductory workshops can be used as an effective tool for this change. For instance, in 2017, the Ministry of Construction and Housing in partnership with Salahaddin University held its first forum to explore and adopt new technologies to the construction sector in the Kurdistan region (MOCAH 2017). More comprehensive forums and presentations can be organised to explain the benefits of collaboration and the effects of collaboration on improving construction industry products that could encourage stakeholders to implement collaborative approaches. Later on, workshops and seminars could aim to create a sufficient implementation system of collaboration. For example, Arayici et al. (2011) described that major benefits can be gained from presentations about the implementation of collaboration and technologies in construction projects such as a rapid increase of awareness. The authors added that resistance to change decreases as practitioners realise the advantages of a new approach.

Through implementing collaboration in the public sector, construction companies will be obligated to use such approaches. This step can make those organisations realise the 
advantages of collaborative working and increase their interest in applying such methods of working in the private sector. Cheng et al. (2000) presented a case study after several companies raised interest in collaborative working, to overcome severe future market challenges, and signed a partnering agreement. The companies cooperated in previous years and completed some projects together but all of them with no partnering experience. After the agreement was signed, companies hired a facilitator with considerable experience in collaborative approaches. The facilitator formed a team consisting of a senior member of each company. The facilitator expanded the concepts of collaborative working to the team and with the support from top management successful partnering was formed. Since construction projects face similar problems in emerging economies (Sweis et al. 2008). Proportionate arrangements can be developed between construction organisations in the Kurdistan region of Iraq. Actually, in Iraqi Kurdistan, a considerable number of international organisations exist that have experience in collaborative approaches of working. KRG could benefit from their experience in legislating and imposing new rules in the construction industry.

Furthermore, considering that scarce literature that exists on collaboration in construction projects in Iraqi Kurdistan, further research is necessary. The KRG needs to build partnerships with academic centres and universities to investigate the situation and to change the adversarial sector of construction to a more collaborative environment. Future research could use factors found in this research and develop systematic approaches to implement each factor individually; for example, it could develop systematic ways to improve communication lines in construction projects in the region. Researchers also need to look at the difference between collaboration practices in the private and public construction sectors. In addition, differences in collaborative working between the various levels of supply chains such as between contractors and their subcontractors should be examined. Since obstacles facing construction are similar across emerging economies, the results of this research can be 
implemented in other developing economies. To date, construction projects use traditional approaches and the industry is fragmented; however, there are opportunities to improve construction practices and move the industry toward collaborative working in Iraqi Kurdistan.

\section{Conclusion}

The research intended to investigate underlying factors required to enable collaboration in the construction in the Kurdistan region of Iraq. It started by gathering global information through a comprehensive review of the literature. Later, an industry-wide questionnaire was used to glean local information and perceptions of construction practitioners regarding the importance of factors for delivering an effective process of collaboration. Six critical factors were extracted through performing exploratory factor analysis on 23 items developed from a synthesis of the literature and perception of practitioners in the construction sector. The critical factors initiated in this investigation were: project vision, behaviour of participants, communication, relationship definition, contractual agreements and systematic process.

To enable collaboration in construction the KRG needs to impose new policies on the construction sector through responsible organisations. It is essential to impose new policies at bid awarding stage and contractor selection. In this process, the KRG could benefit from the experience of international companies that work in the region in legislating and implementing new rules. Since practitioners of the industry are used to adversarial relationships, it was suggested that KRG could work with universities and research centres to broaden awareness toward collaborative approaches by organising training and workshops. Further work and research recommendations have also been demonstrated. 


\section{References}

Abramzon S, Burger N, Glick P, Kumar K, Montemayor CK, Mejia Gonzalez NJ, Nataraj S, Perez-Arce F, Setodji CM. 2016. Calculating the Gross Regional Product of the Kurdistan Region-Iraq. Rand Corporation Santa Monica, CA.

Akintan OA, Morledge R. 2013. Improving the Collaboration between Main Contractors and Subcontractors within Traditional Construction Procurement. Journal of Construction Engineering. 2013:1-11.

Akintoye A, McIntosh G, Fitzgerald E. 2000. A survey of supply chain collaboration and management in the UK construction industry. European journal of purchasing \& supply management. 6(3-4):159-168.

Arayici Y, Coates P, Koskela L, Kagioglou M, Usher C, O'reilly K. 2011. Technology adoption in the BIM implementation for lean architectural practice. Automation in construction. 20(2):189-195.

Arditi D, Gunaydin HM. 1998. Factors that affect process quality in the life cycle of building projects. Journal of construction engineering and management. 124(3):194-203.

Azhar, Kang Y, Ahmad IU. 2014. Factors Influencing Integrated Project Delivery in Publicly Owned Construction Projects: An Information Modelling Perspective. Procedia Engineering. 77:213-221.

Bayramoglu S. 2001. Partnering in construction: Improvement through integration and collaboration. Leadership and Management in Engineering. 1(3):39-43.

Bell J. 2014. Doing Your Research Project: A guide for first-time researchers. McGraw-Hill Education (UK).

Bemelmans J, Voordijk H, Vos B. 2012. Supplier-contractor collaboration in the construction industry: A taxonomic approach to the literature of the 2000-2009 decade. Engineering, Construction and Architectural Management. 19(4):342-368.

Bidabadi ZT, Hosseinalipour M, Hamidizadeh MR, Mohebifar A. 2016. Supply chain collaboration within the Iranian construction industry. Organization, Technology and Management in Construction: an International Journal. 8(1):1437-1445.

Bidabadi ZT, Hosseinalipour M, Hamidizadeh MR, Mohebifar AH, Dorostkar O. 2015. Collaboration: The key to success in construction supply chain.

Black C, Akintoye A, Fitzgerald E. 2000. An analysis of success factors and benefits of partnering in construction. International journal of project management. 18(6):423434. 
Bresnen M, Marshall N. 2000a. Building partnerships: case studies of client-contractor collaboration in the UK construction industry. Construction Management \& Economics. 18(7):819-832.

Bresnen M, Marshall N. 2000b. Partnering in construction: a critical review of issues, problems and dilemmas. Construction Management \& Economics. 18(2):229-237.

Brown JD. 2009. Principal components analysis and exploratory factor analysis \&ndash Definitions, differences, and choices. Statistics. 13(1).

Cao D, Wang G, Li H, Skitmore M, Huang T, Zhang W. 2015. Practices and effectiveness of building information modelling in construction projects in China. Automation in Construction. 49:113-122.

Chan AP, Chan DW, Chiang YH, Tang B-S, Chan EH, Ho KS. 2004. Exploring critical success factors for partnering in construction projects. Journal of construction engineering and management. 130(2):188-198.

Cheng EW, Li H. 2001. Development of a conceptual model of construction partnering. Engineering, Construction and Architectural Management. 8(4):292-303.

Cheng EW, Li H. 2002. Construction partnering process and associated critical success factors: quantitative investigation. Journal of management in engineering. 18(4):194202.

Cheng EW, Li H, Love P. 2000. Establishment of critical success factors for construction partnering. Journal of management in engineering. 16(2):84-92.

Christenson D, Walker DH. 2004. Understanding the role of "vision" in project success. Project Management Journal. 35(3):39-52.

Costello AB, Osborne JW. 2005. Best practices in exploratory factor analysis: Four recommendations for getting the most from your analysis. Practical assessment, research \& evaluation. 10(7):1-9.

Dikmen I, Birgonul MT, Ozorhon B, Eren K. 2008. Critical success factors for partnering in the Turkish construction industry. Conference Proceedings of the 24th Annual ARCOM Conference held in Cardiff.

Elkhalifa A. 2016. The magnitude of barriers facing the development of the construction and building materials industries in developing countries, with special reference to Sudan in Africa. Habitat International. 54:189-198.

Erdogan B, Anumba CJ, Bouchlaghem D, Nielsen Y. 2008. Collaboration environments for construction: Implementation case studies. Journal of Management in Engineering. 24(4):234-244. 
Eriksson PE. 2010. Improving construction supply chain collaboration and performance: a lean construction pilot project. Supply Chain Management: An International Journal. 15(5):394-403.

Faris HMA. 2015. Causes of delays in construction projects in Kurdistan region of Iraq [Dissertation]. University of Portsmouth.

Field A. 2013. Discovering statistics using IBM SPSS statistics. sage.

Floyd FJ, Widaman KF. 1995. Factor analysis in the development and refinement of clinical assessment instruments. Psychological assessment. 7(3):286.

Gerges M, Austin S, Mayouf M, Ahiakwo O, Jaeger M, Saad A, Gohary T-E. 2017. An investigation into the implementation of Building Information Modeling in the Middle East. Journal of Information Technology in Construction (ITcon). 22(1):1-15.

Giang DT, Pheng LS. 2011. Role of construction in economic development: Review of key concepts in the past 40 years. Habitat International. 35(1):118-125.

Grilo A, Zutshi A, Jardim-Goncalves R, Steiger-Garcao A. 2013. Construction collaborative networks: the case study of a building information modelling-based office building project. International Journal of Computer Integrated Manufacturing. 26(1-2):152165.

Haron NA, Soh R, Ana RPZ, Harun AN. 2017. Implementation of Building Information Modelling (BIM) in Malaysia: A Review. Pertanika Journal of Science \& Technology. 25(3).

Hughes D, Williams T, Ren Z. 2012. Differing perspectives on collaboration in construction. Construction Innovation. 12(3):355-368.

Jamieson S. 2004. Likert scales: how to (ab) use them. Medical education. 38(12):1217-1218. Kaiser HF. 1974. An index of factorial simplicity. Psychometrika. 39(1):31-36.

Khalfan MM, McDermott P, Swan W. 2007. Building trust in construction projects. Supply Chain Management: An International Journal. 12(6):385-391.

Koolwijk JSJ, van Oel CJ, Wamelink JWF, Vrijhoef R. 2018. Collaboration and Integration in Project-Based Supply Chains in the Construction Industry. Journal of Management in Engineering. 34(3):04018001.

Koraltan SB, Dikbas A. 2002. An assessment of the applicability of partnering in the Turkish construction sector. Construction Management \& Economics. 20(4):315-321.

Koutsikouri D, Austin S, Dainty A. 2008. Critical success factors in collaborative multidisciplinary design projects. Journal of Engineering, Design and Technology. 6(3):198-226. 
Kożuch B. 2009. The culture of collaboration. Theoretical aspects. Journal of intercultural management. 1(2):17-29.

Kożuch B, Sienkiewicz-Małyjurek K. 2016. Factors of effective inter-organizational collaboration: a framework for public management. Transylvanian Review of Administrative Sciences. 12(47):97-115.

Latham SM. 1994. Constructing the team.

Liu Y, van Nederveen S, Hertogh M. 2017. Understanding effects of BIM on collaborative design and construction: An empirical study in China. International Journal of Project Management. 35(4):686-698.

Lu S, Yan H. 2007. A model for evaluating the applicability of partnering in construction. International Journal of Project Management. 25(2):164-170.

Meng X. 2012. The effect of relationship management on project performance in construction. International Journal of Project Management. 30(2):188-198.

Meng X. 2013. Change in UK construction: moving toward supply chain collaboration. Journal of Civil Engineering and Management. 19(3):422-432.

Mills A. 2001. A systematic approach to risk management for construction. Structural survey. 19(5):245-252.

MOCAH. 2017. Kurdistan Regional Government Construction Forum Proceedings Report. Erbil: Ministry of Construction and Housing.

Morrell P. 2015. Collaboration for Change: The Edge Commission Report on the Future of Professionalism| Edge Debate. London: The Edge Commission, May.

Motawa I, Carter K. 2013. Sustainable BIM-based Evaluation of Buildings. Procedia - Social and Behavioral Sciences. 74:419-428.

Muhammed TA. 2015. DELAYS IN CONSTRUCTION.

Mustafa FA. 2017. Performance assessment of buildings via post-occupancy evaluation: A case study of the building of the architecture and software engineering departments in Salahaddin University-Erbil, Iraq. Frontiers of Architectural Research. 6(3):412-429.

Nursin A, Latief Y. 2018. Critical Success Factors in Developing Collaborative Design-Build Project Team to Improve Project Performance. MATEC Web of Conferences.

Nyström J. 2005. The definition of partnering as a Wittgenstein family-resemblance concept. Construction Management and Economics. 23(5):473-481.

Challenges of construction industries in developing countries: Lessons from various countries. 2nd International Conference on Construction in Developing Countries: 
Challenges Facing the Construction Industry in Developing Countries, Gaborone, November; 2000.

Ofori G. 2007. Construction in Developing Countries. Construction Management and Economics. 25(1):1-6.

Patel H, Pettitt M, Wilson JR. 2012. Factors of collaborative working: a framework for a collaboration model. Applied ergonomics. 43(1):1-26.

Phua FTT. 2006. When is construction partnering likely to happen? An empirical examination of the role of institutional norms. Construction Management and Economics. 24(6):615-624.

Rahman SHA, Endut IR, Faisol N, Paydar S. 2014. The importance of collaboration in construction industry from contractors' perspectives. Procedia-Social and Behavioral Sciences. 129:414-421.

RTI International. 2008. Kurdistan Region Economic Development Assessment.

Shelbourn M, Bouchlaghem N, Anumba C, Carrillo P. 2007. Planning and implementation of effective collaboration in construction projects. Construction Innovation. 7(4):357377.

Shen, Wu Y. 2005. Risk concession model for build/operate/transfer contract projects. Journal of construction engineering and management. 131(2):211-220.

Sweis G, Sweis R, Hammad AA, Shboul A. 2008. Delays in construction projects: The case of Jordan. International Journal of Project Management. 26(6):665-674.

Vaaland TI. 2004. Improving project collaboration: start with the conflicts. International Journal of Project Management. 22(6):447-454.

van Gassel FJM, Láscaris-Comneno T, Maas GJ. 2014. The conditions for successful automated collaboration in construction. Automation in Construction. 39:85-92.

Winch GM. 2010. Managing construction projects. John Wiley \& Sons.

Wong WK, Cheung SO, Yiu TW, Pang HY. 2008. A framework for trust in construction contracting. International Journal of Project Management. 26(8):821-829.

Wu S, Greenwood D, Steel G. 2008. Exploring the attributes of collaborative working in construction industry. Northumbria Working Paper Series: Interdisciplinary Studies in the Built and Virtual Environment. 1(2):135-147.

Xue X, Shen Q, Ren Z. 2010. Critical review of collaborative working in construction projects: business environment and human behaviors. Journal of Management in Engineering. 26(4):196-208. 
Yeung JF, Chan AP, Chan DW. 2007. The definition of alliancing in construction as a Wittgenstein family-resemblance concept. International Journal of Project Management. 25(3):219-231.

Zebari HN, Ibrahim RK. 2016. Methods \& Strategies For Sustainable Architecture In Kurdistan Region, Iraq. Procedia Environmental Sciences. 34:202-211. 